\title{
Predictors of Clinical and Immunological Failure Among Patients on First-Line Antiretroviral Therapy (ART) in Southwest Ethiopia
}

This article was published in the following Dove Press journal: HIVIAIDS - Research and Palliative Care

\author{
Adane Asefa ${ }^{\prime}$ \\ Zufan Asaye 2 \\ Abiot Girma ${ }^{3}$ \\ Desta Hiko ${ }^{3}$ \\ 'Department of Public Health, College of \\ Health Science, Mizan-Tepi University, \\ Mizan-Aman, Ethiopia; ${ }^{2}$ Department of \\ Statistics, College of Natural Science, \\ Mizan-Tepi University, Mizan-Aman, \\ Ethiopia; ${ }^{3}$ Department of Epidemiology, \\ Faculty of Public Health, Jimma \\ University, Jimma, Ethiopia
}

Background: Global expanded access to antiretroviral therapy has led to a rapid fall in the number of people dying from HIV-related causes. However, the remarkable achievement recorded in reducing morbidity and mortality has been affected due to the occurrence of firstline ART failure. The study was intended to identify predictors of clinical and immunologic failure of first-line ART in southwest Ethiopia.

Methods: A retrospective cohort study was conducted among 737 randomly selected ART patients from $1^{\text {st }}$ January 2010 to $30^{\text {th }}$ June 2016 . Trained data collectors collected the data from the patients' follow-up charts and electronic databases. The Kaplan Meier (KM) curve was used to describe the probability of survival time to antiretroviral treatment failure. Variables with a p-value of $\leq 0.05$ in a multivariable cox-proportional hazard model were statistically significant predictors of first-line ART failure.

Results: Among 737 HIV patients on ART followed retrospectively, 445 (60.4\%) were females. During the follow-up period, the incidence rate of treatment failure was 7.3 per 100 person-year observations, and the highest rate was observed during the first 6 to 12 months of ART initiation. Not disclosing HIV status (AHR= 2.04, 95\% CI: 1.32-3.16), being bedridden (AHR= 2.01, 95\% CI: 1.02-3.98) and low hemoglobin at ART initiation (AHR= 2.02, 95\% CI: 1.29-3.13) were associated with an increased hazard rate for first-line ART failure.

Conclusion: The study showed that predictors of first-line ART treatment failure are modifiable. Therefore, these factors should be addressed during routine care of HIV patients by health care providers to preserve the rapid exhaustion of first-line medications, improve the quality of life of the patients and reduce HIV/AIDS related deaths.

Keywords: ART, ART failure, antiretroviral therapy, HIV, survival analysis

\section{Background}

HIV/AIDS remains to have devastating health effects globally, with over 0.95 million HIV/AIDS-related deaths, and more than 36 million people living with HIV in 2017 . $^{1}$ Universal access to antiretroviral therapy (ART) has led to an increased number of patients receiving ART; ${ }^{2}$ consequently, the number of people dying from HIV related causes had been decreased significantly across the world. ${ }^{3,4}$ Nonetheless, as the number of people using ART increased, the percentage of treatment failure also increased. $^{5,6}$ In 2010, WHO estimated about 500,000 to 800,000 patients required switching to second-line regimens mainly due to first-line failure. ${ }^{7}$ Also, another report showed, about $6 \%$ of patients receiving first-line therapy need switching to second-line regimens in any given year in Sub-Sahara Africa. ${ }^{4}$ Other studies
Correspondence: Adane Asefa Department of Public Health, College of Health Science, Mizan-Tepi University, Mizan-Aman, Ethiopia

Email adane779@gmail.com 
from some sub-Saharan Africa countries also showed the prevalence of treatment failure varied between $11 \%$ to $32.2 \% .^{8-11}$ In Ethiopia, the prevalence of first-line ART failure ranges from $2.4 \%$ to $17.6 \%{ }^{12-15}$

A rampant first-line ART failure imposed a major challenge to HIV prevention and control programs. The alternate treatments after first-line ART failure are limited due to the high cost and limited options of alternative medications. ${ }^{16}$ Furthermore, patients failed for first-line medications are more likely to fail again for second-line regimens. Also, switching to second-line treatments expose the patients to a higher of side effects, and more likelihood of drug resistance and treatment fatigue. ${ }^{17,18}$ Besides, the proportion of patients suffering from unfavorable outcomes such as co-morbidity and death is high among patients with first-line ART failure. ${ }^{13}$ Also, staying on a failed first-line therapy is associated with an increased risk of mortality. ${ }^{17,19}$ Furthermore, early failure of firstline antiretroviral medications causes rapid exhaustion of treatment options' of relatively safe and low cost. $^{20}$ Different studies were identified predictors clinical and immunological failures, but there are inconsistencies regarding factors affecting ART failures. ${ }^{13,21,22}$

WHO strongly recommends the use of the viral load as the preferred monitoring approach to diagnose and confirm ART failure. ${ }^{23}$ But, viral load test is not available in lowincome countries like Ethiopia for routine monitoring, and majorities of HIV care settings use CD4 count and clinical monitoring to diagnose treatment failure. This study was aimed to identify predictors of clinical and immunologic failure of first-line ART in southwest Ethiopia.

\section{Methods}

\section{Study Setting and Design}

A retrospective cohort study was conducted in Jimma University Specialized Hospital (JUSH) southwest Ethiopia from $1^{\text {st }}$ of January 2010 to $30^{\text {th }}$ June 2016. The Hospital is located in Jimma town, $356 \mathrm{~km}$ southwest of Addis Ababa. Currently, it is the only teaching and referral hospital in the southwestern part of the country. JUTH is providing services for more than 15 million people that come from its catchment area. The Hospital has been providing ART services since 2005 free of charge. In addition to ART service, it also offers voluntary counseling and testing (VCT), provider initiative counseling and testing (PICT) and PMTC services. During the study period, the Hospital is delivering HIV care services for about 2882 patients. JUSH uses WHO clinical and immunologic criteria routinely to monitor ART failure.

\section{Study Population}

The study population was all randomly selected adults on first-line ART for at least six months, and who initiated ART between January 1, 2010, and December 30, 2015. The follow-up period was a time between January 1, 2010, and June 30, 2016, to ensure every patient were on ART for at least 6 months. This was due to the WHO recommendation of a patient should take ART for at least six months to diagnosis treatment failure. Patients who transferred-in from other health facilities or discontinued the treatment (lost) or who's their date of ART initiation and the last visit were not recorded, and/or who had less than two CD4 tests recorded were excluded due to incomplete baseline and follow up information.

\section{Sample Size and Sampling Procedure}

The sample size for the study was determined by using STATA 113 menu (Stata Corp, College Station, Texas USA) sample size determination for the cox-model. We considered $\alpha=5 \%$, power $=80 \%$ and standard deviation $=0.5$ (default value), proportion of event (ART failure) $=0.024 \%$ and hazard ration $=3.79$. The final sample size was $737 \mathrm{HIV}$ patients taking ART. Before selecting study participants, records of all illegible ART clients' were filtered out from the ART register and database, and the sampling frame was generated using a unique ART number. Finally, a computergenerated simple random sampling technique was employed to recruit study participants.

\section{Study Variables}

The dependent variable was time to first-line ART failure (in a month). The independent variables were sociodemographic factors (age, sex, religion, marital status, level of education, occupational status), medical conditions (DC4 count, hemoglobin level, functional status, and WHO stages and opportunistic infection and/or HIV related cancer), nutritional status (BMI), behavioral factors (adherence to ART and HIV disclosure) and drug-related factors (ART regimens and ART-related side effect).

\section{Data Collection Procedure}

A structured data extraction tool was developed from standard ART registers, patients follow up charts and electronic databases. Trained data collectors (ART clerk) were extracted data from patients' follow-up chart, and 
ART registers as well as the electronic database. During follow-up, data were generated at two points retrospectively. The first was at baseline, which was records nearest to ART initiation. The second data point was at a time when the status of the patient such as either censoring or event (ART failure) ascertained. During data collection, there was intensive supervision for completeness, consistency, and accuracy. Every incomplete checklist sent back to the corresponding data collector for correction by using unique ART numbers.

\section{Measurements}

The data were obtained retrospectively from ART registers, patients follow up charts and electronic databases. ART failure was measured using immunologic and clinical criteria based on WHO guidelines. ${ }^{23}$ Immunologic failure was defined as ${ }^{1}$ decrease in CD4 cell count to pre-treatment or below, ${ }^{2} 50 \%$ decrease in CD4 cell count from the peak during treatment or $^{3}$ two consecutive CD4 cell counts less than 100 cells $/ \mathrm{mL}$. The Hospital was using Flow Cytometric test to enumerate CD4 cells. The quality of CD4 testing had been monitored by following standard guidelines (internal quality assessment scheme and proficiency test or external quality assessment scheme). The CD4 cell counting routinely is done every 6 months to monitor response to treatment or diagnose treatment failure.

Clinical failure define as the occurrence new or recurrent WHO stage 4 conditions (HIV wasting syndrome, pneumocystis pneumonia, recurrent severe bacterial pneumonia, chronic herpes simplex infection, esophageal candidiasis (or candidiasis of trachea, bronchi or lungs), extra-pulmonary tuberculosis, Kaposi sarcoma, cytomegalovirus infection, central nervous system toxoplasmosis, HIV encephalopathy, extra-pulmonary Cryptococcus, including meningitis, disseminated nontuberculous mycobacterial infection, progressive multifocal leukoencephalopathy, chronic cryptosporidiosis, chronic isosporiasis, disseminated mycosis (extra-pulmonary histoplasmosis, coccidioidomycosis), lymphoma, symptomatic HIV-associated nephropathy or cardiomyopathy, recurrent septicemia (including nontyphoidal salmonella), invasive cervical carcinoma and atypical disseminated leishmaniasis) or certain stage 3 conditions (pulmonary TB and severe bacterial infections) that is not due to immune reconstitution inflammatory syndrome (IRIS). Individuals with immunologic and/or clinical failures were considered to have ART failure in this study. We had used immunologic and clinical criteria to measure ART failure because of the Hospital was using these standards to monitor response to treatment.

\section{Operational Definition}

Survival time to ART failure was defined as the time (in months) between ART initiation and the occurrence of ART failure as documented by ART physician on patient's card or electronic ART database.

Censored Patients who were lost, transferred out, died due to not treatment failure or did not experience the event (ART failure) during the follow-up period as documented by ART physician on patient's card or electronic ART database.

Working functional status clients who could perform usual work in or out of the house as documented by a clinician on patient charts or database

Ambulatory functional status clients who could perform daily living activities as documented by clinicians on patient charts or databases.

Bedridden functional status designate to clients who were not able to perform activities of daily living as documented by clinicians in patient's clinical charts or databases.

Adherence to ART is good if the percentage of the missed dose was between $>95 \%$ ( $<2$ doses of 30 doses or $<3$ dose of 60 doses) as documented by clinicians in patient's clinical charts or databases.

Adherence to ART is fair if the percentage of the missed dose was between $85-94 \%$ (3-5 doses of 30 doses or 3-9 doses of 60 doses) as documented by clinicians in patient's clinical charts or databases.

Adherence to ART is poor if the percentage of the missed dose was between $<85 \%$ ( $>6$ doses of 30 doses or $>9$ doses of 60 doses) as documented by clinicians in patient's clinical charts or databases.

\section{Data Processing and Analysis}

The data were cleaned, coded and entered into Epi data version 3.1 and exported to SPSS version 21 for analysis. Data exploration was done to identify unexpected values and outliers, and the cleaned and compiled data were prepared for final analysis. Proportion, mean, medians, interquartile range (IQR) and standard deviation (SD) were computed for categorical and continuous variables as supposed necessary. Kaplan-Meier (KM) survival analysis was used to estimate the survival time to first-line ART failure. Bi-variable and a multivariable cox-proportional hazards regression model were employed to identify the predictors of treatment and variables with a p-value less than 0.25 were considered as candidates for the multivariable 
model. Both crude and adjusted hazard ratios (HRs) with $95 \%$ confidence intervals were reported, and variables with p-values $<0.05$ in the multivariable Cox regression model were considered statistically significant predictors of treatment failure.

\section{Ethical Consideration}

Ethical clearance was obtained from the Institutional Review Board (IBR) of Jimma University Institute of Health Sciences to undertake the study. A permission letter was obtained from the Hospital to access patients' data. We used unique ART numbers as patients' identifiers, and information collected from clients' documents was kept anonymous and confidential.

\section{Results}

\section{Description of the Cohort}

Among 737 patients included in the study, 445 (60.4\%) were female and $68(15.3 \%)$ of them were experienced treatment failure during the follow-up period. The mean (SD) age of patients at enrollment was $33.31(\mathrm{SD}=8.86)$ years. Among the total 384 (52.1\%) married study subjects at the time of ART initiation, 62(16.1\%) were encountered ART failure. More than half (53.7\%) were Orthodox Christian and $17.7 \%$ of them had treatment failure. Among study subjects who had no formal education, $15.6 \%$ were developed treatment failure. The proportion of treatment failure among patients who were unable to work due to illness at enrollment was $37.7 \%$. Out of 206 (29.8\%) ART clients that did not disclose their serostatus, $30.6 \%$ were encountered first-line ART failure. (Table 1).

The majority, $510(69.2 \%)$ were working functional status at ART initiation and only $11.1 \%$ of them developed treatment failure. Among 187 ambulatory patients at ART initiation, $31.6 \%$ had developed treatment failure. Out of 343 (46.5\%) participants who were at advanced baseline WHO stages (stage III or IV), 27.7\% experienced first-line ART failure. At ART initiation, the median and interquartile range of CD4 count was 198 and 167 cells $/ \mu \mathrm{L}$ respectively. Among ART clients started treatment at CD4 less than 200 cells $/ \mu \mathrm{L}, 53(31.4 \%)$ were developed treatment failure. More than half $(55.4 \%)$ of the subjects were in normal body mass index $\left(18.5-25.9 \mathrm{~kg} / \mathrm{m}^{2}\right)$ at ART initiation. About $15.4 \%$ of participants within the normal baseline body mass index $\left(18.5-24.9 \mathrm{k} / \mathrm{m}^{2}\right)$ developed first-line ART failure. During follow - up period, 253(34.1\%) patients had at least one opportunistic infection or HIV related cancer and $35.6 \%$ of them were had ART failure. Among total cohorts, the majority $(80.3 \%)$ started treatment with TDF-3TC- EFV regimen and followed by AZT3TC-NVP (12.5\%). The prevalence of ART failure among patients started treatment with DF-3TC- EFV, was $17.7 \%$ and it was $11.8 \%$ among those who stared with AZT-3TCNVP. Out of the clients who developed ART related side effects, $17.6 \%$ experience treatment failure (Table 2).

\section{Time to Treatment Failure}

Among 737 patients followed retrospectively for a median time of 26.27 months and 1807 person-years of observation (PYO), 132 (17.9\%) patients developed ART failure. The incidence rate (IR) of treatment failure was 7.3 cases per 100 person-years of observation ( $\mathrm{IR}=0.073,95 \% \mathrm{CI}$ : $0.062-0.087)$. The highest rate treatment failures had occurred between 6 and 12 months of ART initiation as it was revealed by the rapid rise of the hazard curve during this period. The cumulative probability of ART failure at the end of $10,12,18,24,36,60$ and 73.3 months was about $0.06 \%, 0.07,0.10,0.14,0.2,0.29$ and $0.36 \%$ respectively (Figure 1).

\section{Predictors of First-Line Treatment Failure}

During bivariate cox-proportional hazard analysis sex, marital status, level of education, employment status at enrollment, functional status, HIV disclosure, WHO stage, CD4 count, hemoglobin, body mass index and history of ART related side effect had a $p$-value of $\leq 0.25$; hence, they were candidates for the multivariable model. However, age, religion, TB-HIV co-infection at enrollment and ART adherence were demonstrated p-values of $>0.25$; therefore, they were excluded from the multivariable analysis.

After controlling all potential confounders in multivariable Cox proportional regression, HIV status disclosure, baseline functional status, and hemoglobin level were independent predictors of first-line ART failure. Those patients who did not disclose their HIV status to anyone experienced treatment failure at a rate of $2.04(\mathrm{AHR}=2.04,95 \% \mathrm{CI}$ : 1.32-3.16) times higher than those disclosed their HIV status to others. The rate of treatment failure among Bed Ridden patients at ART initiation was 2.01 times higher compared to working functional status (ARH=2.01, 95\% CI: 1.01-3.13). Individuals with baseline hemoglobin of $\leq 11 \mathrm{mg} / \mathrm{dl}$ had 2.02 $(\mathrm{AHR}=2.02,95 \% \mathrm{CI}: 1.29-3.13)$ times increased hazard rate of first-line ART failure when compared to those with baseline hemoglobin $>11 \mathrm{mg} / \mathrm{dl}$. (Table 3 ). 
Table I Baseline Socio-Demographic Characteristics of Patients' on ART in JUSH Between Ist January 2010 and 30th June 20I6, Ethiopia

\begin{tabular}{|c|c|c|c|}
\hline \multirow[t]{3}{*}{ Variables } & \multirow[t]{3}{*}{ N (\%) } & \multicolumn{2}{|l|}{ ART Status } \\
\hline & & ART Failure & Censored \\
\hline & & $\mathbf{N}(\%)$ & N (\%) \\
\hline \multicolumn{4}{|l|}{ Age group } \\
\hline $18-24$ & $102(13.8)$ & $16(15.7)$ & $86(84.3)$ \\
\hline $25-34$ & $322(43.7)$ & $58(18.0)$ & $264(82.0)$ \\
\hline $35-44$ & $216(29.3)$ & $42(19.4)$ & $174(80.6)$ \\
\hline $45-54$ & $80(10.9)$ & $12(15.0)$ & $68(85.0)$ \\
\hline$\geq 55$ & $17(2.3)$ & $4(23.5)$ & $13(76.5)$ \\
\hline \multicolumn{4}{|l|}{ Sex } \\
\hline Male & $292(39.6)$ & $64(21.9)$ & $228(78.1)$ \\
\hline Female & $445(60.4)$ & $68(15.3)$ & $377(84.7)$ \\
\hline \multicolumn{4}{|l|}{ Marital status } \\
\hline Never married & $136(18.4)$ & $27(19.9)$ & $109(80.1)$ \\
\hline Married & $384(52.1)$ & $62(16.1)$ & $322(83.9)$ \\
\hline Divorced & $81(11.0)$ & $13(16.0)$ & $68(84.0)$ \\
\hline Widowed & $64(8.7)$ & $15(23.4)$ & $49(76.6)$ \\
\hline Separated & $72(9.8)$ & $15(20.8)$ & $57(79.2)$ \\
\hline \multicolumn{4}{|l|}{ Religion } \\
\hline Orthodox & $396(53.7)$ & $70(17.7)$ & $326(82.3)$ \\
\hline Muslim & $263(35.7)$ & $44(16.7)$ & $219(83.3)$ \\
\hline Other** & $78(10.6)$ & $18(23.1)$ & $60(76.9)$ \\
\hline \multicolumn{4}{|l|}{ Level of Education } \\
\hline No formal Education & $96(13.0)$ & $15(15.6)$ & $81(84.4)$ \\
\hline Primary Education & $164(22.3)$ & $34(20.7)$ & $130(79.3)$ \\
\hline Secondary education & $278(37.7)$ & $45(16.2)$ & $233(83.8)$ \\
\hline Tertiary & $199(27.0)$ & $38(19.1)$ & $|6|(80.9)$ \\
\hline \multicolumn{4}{|l|}{ Employment status at enrollment } \\
\hline Working full time & $320(43.4)$ & $43(13.4)$ & $277(86.6)$ \\
\hline Unemployed & $328(44.5)$ & $58(17.7)$ & $270(82.3)$ \\
\hline Not working due to ill health & $61(8.3)$ & $23(37.7)$ & $38(62.3)$ \\
\hline Working part-time & $28(3.8)$ & $8(28.6)$ & $20(71.4)$ \\
\hline \multicolumn{4}{|l|}{ HIV status disclosure at enrollment } \\
\hline Yes & $468(70.2)$ & $61(12.6)$ & $425(87.4)$ \\
\hline No & $206(29.8)$ & $63(30.6)$ & $143(69.4)$ \\
\hline
\end{tabular}

Note: **Protestant and Catholic.

\section{Discussion}

The study revealed that treatment failure occurred among 132 clients during 1807 person-years of observation giving an incidence rate of 7.3 (95\% CI: 6.2-8.7) per 100 PYO and the highest rate of failure occurred during early months of ART initiation. Furthermore, HIV status disclosure, baseline functional status, and low baseline hemoglobin $(\leq 11 \mathrm{mg} / \mathrm{dl})$ were independent predictors of first-line ART failure.
The highest rate of treatment failure was observed during the first 6-12 months of ART initiation. This finding is in line with studies conducted in Bale Zones and Debremarkos Hospital. ${ }^{13,22}$ The highest rate of failure this period could be due to the side effects of medication and not disclosing HIV status in the early months of ART initiation. Most patients develop ART related side effects during the earlier phase of ART initiation. Besides, a study conducted in Debremarkos Hospital, Ethiopia reported that the probability 
Table 2 Baseline and Follow Up Medical and ART-Related Factors Patients' on ART at Jimma University Specialized Hospital Between I January 2010 and 30 June 2016

\begin{tabular}{|c|c|c|c|}
\hline \multirow[t]{3}{*}{ Variable } & \multirow[t]{3}{*}{$\mathbf{N}(\%)$} & \multicolumn{2}{|l|}{ ART Status } \\
\hline & & ART Failure & Censored \\
\hline & & $\mathbf{N}(\%)$ & $\mathbf{N}(\%)$ \\
\hline \multicolumn{4}{|c|}{ Baseline functional status } \\
\hline Working & $510(69.2)$ & $57(\mid 1.2)$ & $453(88.8)$ \\
\hline Ambulatory & $187(25.4)$ & $59(31.6)$ & $128(68.4)$ \\
\hline Bedridden & $40(5.4)$ & $16(40.0)$ & $24(60.0)$ \\
\hline \multicolumn{4}{|c|}{ WHO stage at ART initiation } \\
\hline Stage I or II & $394(53.5)$ & $37(9.4)$ & $357(90.6)$ \\
\hline Stage III or IV & $343(46.5)$ & $95(27.7)$ & $248(72.3)$ \\
\hline \multicolumn{4}{|c|}{ Baseline CD4 count (cell/ $/ \mathrm{L}$ ) } \\
\hline$\leq 100$ & $169(22.9)$ & $53(31.4)$ & $116(68.6)$ \\
\hline$>100$ & $568(77.1)$ & $79(13.9)$ & $489(86.6)$ \\
\hline \multicolumn{4}{|c|}{ Baseline hemoglobin (mg/dl) } \\
\hline$\leq 11$ & $132(21.3)$ & $53(40.2)$ & $79(59.8)$ \\
\hline$>11$ & $474(78.7)$ & $63(13.3)$ & $4 I I(86.7)$ \\
\hline \multicolumn{4}{|c|}{ Baseline BMI (kg/m²) } \\
\hline$<18.5$ & $238(33.0)$ & $6 I(25.6)$ & I77(74.4) \\
\hline $18.5-24.9$ & $408(56.5)$ & $63(15.4)$ & $345(84.6)$ \\
\hline$\geq 25$ & $76(10.5)$ & $6(7.9)$ & $70(92.1)$ \\
\hline \multicolumn{4}{|c|}{ OI/HIV related cancer(at least one) } \\
\hline Yes & $253(34.3)$ & $90(35.6)$ & $163(64.4)$ \\
\hline No & $484(65.7)$ & $42(8.7)$ & $442(91.3)$ \\
\hline \multicolumn{4}{|c|}{ TB co-infection at enrollment to HIV care } \\
\hline Yes & $179(24.3)$ & $27(15.1)$ & I52(84.9) \\
\hline No & $558(75.7)$ & $105(18.8)$ & $453(81.2)$ \\
\hline \multicolumn{4}{|l|}{ ART regimen } \\
\hline d4t-3TC-NVP & $6(0.8)$ & $\mathrm{I}(16.7)$ & $5(83.3)$ \\
\hline d4t-3TC-EFV & $5(0.7)$ & $\mathrm{I}(20)$ & $4(20)$ \\
\hline AZT-3TC-NVP & $92(12.5)$ & $19(20.7)$ & $73(79.3)$ \\
\hline AZT-3TC-EFV & $25(3.4)$ & $21(84)$ & $4(16)$ \\
\hline TDF-3TC- EFV & $592(80.3)$ & $105(17.7)$ & $487(82.3)$ \\
\hline TDF-3TC- NVP & $17(2.3)$ & $2(11.8)$ & $15(88.2)$ \\
\hline \multicolumn{4}{|c|}{ History of Side effect throughout follow up } \\
\hline Yes & $44(6.0)$ & $10(22.7)$ & $34(77.3)$ \\
\hline No & 693(94.0) & $122(17.6)$ & $57 \mid(82.4)$ \\
\hline \multicolumn{4}{|c|}{ Episode of fair or poor } \\
\hline \multicolumn{4}{|c|}{ ART adherence } \\
\hline At least one & $244(33.1)$ & $99(40.6)$ & $145(59.4)$ \\
\hline None & $493(66.9)$ & $33(6.7)$ & $460(93.3)$ \\
\hline
\end{tabular}

of experiencing treatment failure at the end of $12,18,24$ and 36 months on ART was $12 \%, 18 \%, 21 \%$, and $23 \%$ respectively which is higher than the finding in the current study. ${ }^{22}$ This inconsistency could be due to the difference in the follow-up period, the variation in sample size, initiation criteria, behavioral related factors, and the criteria used to identify treatment failure between these settings.

This study showed, not disclosing HIV status to family or other persons was associated with an increased risk of treatment failure. The finding is in line with a study 


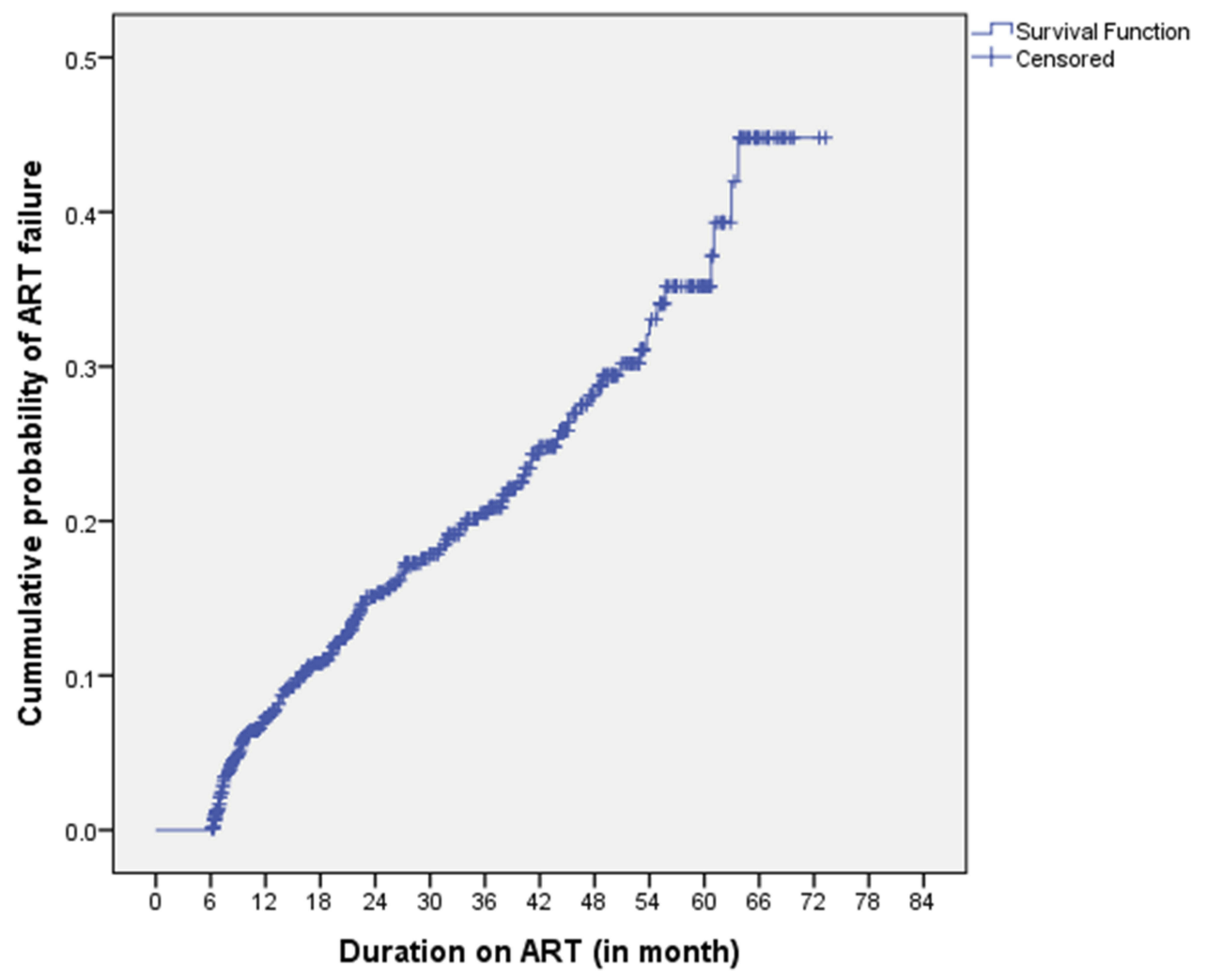

Figure I Cumulative probability of first-line ART failure among patients in JUSH between Ist January 20I0 and 30th June 20I6, Ethiopia.

conducted at St. Luke and Tulu bolo Hospital, ${ }^{14}$ but it contrasts with the study conducted in Addis Ababa private facilities, which showed HIV patients who did not disclose their HIV status had a lower risk of treatment failure. ${ }^{12}$ HIV status disclosure could have positive benefits such as high social support, stronger family cohesion, and relationships, reductions in anxiety and depression, good adherence to medication and improvements in physical health which might lead to better respond to treatment. In contrast, non-disclosure might lead to non-adherence as a way to conceal the disease from others. Also, disclosing could result in a negative outcome such as stigma and discrimination, lack of a strong social network, feelings of shame and guilt regarding one's HIV status which might cause treatment failure and poor health outcomes. ${ }^{24}$ Hence, the inconsistencies between the literature regarding the association between treatment failure and HIV status disclosure probably due to these negative and positive effects of disclosure.

It was demonstrated that being bedridden functional status at ART initiation was associated with an increased rate of treatment failure compared to working functional status. The finding is consistent with the study conducted in Bale Zone, Ethiopia. ${ }^{13}$ But, this finding contrasts with the studies conducted in St. Luke and Tulu Bolo hospitals and Tanzania, which indicated baseline functional status did not have an association with the hazard of treatment failure. ${ }^{14,25}$ This inconsistency could be due to differences in criteria used to measure ART failure and follow -up period across studies. Bedridden functional status ART initiation reflects the deprived health condition and immunologic deterioration of patients. Therefore, patients are at increased risk of opportunistic infection, increased the burden of drugs and toxicity that could negatively affect adherence to ART medications and possibly increases the risk of ATR failure.

The study also revealed baseline hemoglobin has a significant association with ART failure. Patients with baseline hemoglobin less or equal to $11 \mathrm{mg} / \mathrm{dl}$ had two times increased risk of first-line ART failure compared to those with baseline hemoglobin of greater than $11 \mathrm{mg} / \mathrm{dl}$. The result is supported by finding from a study conducted in Johannesburg, South Africa. ${ }^{26}$ In most the case, anemic patients are more likely to have advanced immunosuppression and a higher rate of comorbidities which could impose a negative effect of response to ARV treatments. Evidence from other studies also shows anemia at ART initiation associated with increased mortality, disease progression (poor virologic response) and reduced quality of life. ${ }^{27-29}$ 
Table 3 Predictors of First-Line ART Failure Among Patients on ART in JUSH Between I ${ }^{\text {st }}$ January 2010 and $30^{\text {th }}$ June 2016

\begin{tabular}{|c|c|c|c|c|}
\hline \multirow[t]{3}{*}{ Variables } & \multicolumn{2}{|c|}{ ART Failure } & \multirow[t]{3}{*}{ CHR $(95 \% \mathrm{Cl})$} & \multirow[t]{3}{*}{ AHR (95\% Cl) } \\
\hline & Yes & Censored & & \\
\hline & $\mathbf{N}(\%)$ & $\mathbf{N}(\%)$ & & \\
\hline \multicolumn{5}{|l|}{ Sex } \\
\hline Male & \multirow{2}{*}{$\begin{array}{l}64(21.9) \\
68(15.3)\end{array}$} & \multirow{2}{*}{$\begin{array}{l}228(78.1) \\
377(84.7)\end{array}$} & $1.43(1.02-2.02)$ & $1.40(0.89-2.20)$ \\
\hline Female & & & \multicolumn{2}{|l|}{1} \\
\hline \multicolumn{5}{|l|}{ Marital status } \\
\hline Never married & $27(19.9)$ & $109(80.1)$ & $1.32(0.84-2.02)$ & $1.30(0.66-2.59)$ \\
\hline Married & $62(16.1)$ & $322(83.9)$ & \multicolumn{2}{|l|}{1} \\
\hline Divorced & $13(16.0)$ & $68(84.0)$ & $1.16(0.63-2.11)$ & $0.87(0.40-1.86)$ \\
\hline Widowed & $15(23.4)$ & $49(76.6)$ & $1.53(0.87-2.69)$ & $1.01(0.44-2.31)$ \\
\hline Separated & $15(20.8)$ & $57(79.2)$ & $1.6(0.91-2.18)$ & $1.99(0.86-4.61)$ \\
\hline \multicolumn{5}{|l|}{ Level of Education } \\
\hline No formal Education & $15(15.6)$ & $8 I(84.4)$ & $0.66(0.35-1.20)$ & $0.52(0.22-1.25)$ \\
\hline Primary Education & $34(20.7)$ & $130(79.3)$ & \multicolumn{2}{|l|}{1} \\
\hline Secondary education & $45(16.2)$ & $233(83.8)$ & $0.62(0.49-1.19)$ & $0.94(0.56-1.56)$ \\
\hline Tertiary & $38(19.1)$ & $161(80.9)$ & $0.87(0.54-1.38)$ & $0.85(0.49-1.48)$ \\
\hline \multicolumn{5}{|l|}{ Employment status at enrollment } \\
\hline Working full time & $43(13.4)$ & $277(86.6)$ & \multicolumn{2}{|l|}{1} \\
\hline Unemployed & $58(17.7)$ & $270(82.3)$ & $1.37(0.92-2.02)$ & $1.01(0.62-1.64)$ \\
\hline Not working due to ill health & $23(37.7)$ & $38(62.3)$ & $3.09(1.86-5.14)$ & $1.03(0.53-2.01)$ \\
\hline Working part-time & $8(28.6)$ & $20(71.4)$ & $2.45(1.15-5.23)$ & $1.38(0.5 \mathrm{I}-3.77)$ \\
\hline \multicolumn{5}{|l|}{ HIV status Disclosure } \\
\hline Yes & $61(12.6)$ & $425(87.4)$ & \multicolumn{2}{|l|}{1} \\
\hline No & $63(30.6)$ & $143(69.4)$ & $2.98(2.09-4.26)$ & $2.04(1.32-3.16)^{@}$ \\
\hline \multicolumn{5}{|l|}{ Baseline functional status } \\
\hline Working & $57(11.2)$ & $453(88.8)$ & \multicolumn{2}{|l|}{1} \\
\hline Ambulatory & $59(31.6)$ & $128(68.4)$ & $3.16(2.19-4.54)$ & $1.26(075-2.11)$ \\
\hline Bedridden & $16(40.0)$ & $24(60.0)$ & $4.53(2.59-7.91)$ & $2.01(1.02-3.98)^{@}$ \\
\hline \multicolumn{5}{|l|}{ WHO stage at ART initiation } \\
\hline Stage I or II & $37(9.4)$ & $357(90.6)$ & \multicolumn{2}{|l|}{1} \\
\hline Stage III or IV & $95(27.7)$ & $248(72.3)$ & $3.07(2.10-4.49)$ & $1.52(0.89-2.62)$ \\
\hline \multicolumn{5}{|l|}{ Baseline CD4 count(cell/ $\mu \mathrm{L})$} \\
\hline$\leq 100$ & $53(31.4)$ & $116(68.6)$ & $2.32(1.64-3.29)$ & $1.51(0.98-2.35)$ \\
\hline$>100$ & 79 (13.9) & $489(86.6)$ & \multicolumn{2}{|l|}{ I } \\
\hline \multicolumn{5}{|l|}{ Baseline hemoglobin (mg/dl) } \\
\hline$\leq \mathrm{II}$ & $53(40.2)$ & $79(59.8)$ & $3.29(2.28-4.75)$ & $2.02(1.29-3.13)^{@}$ \\
\hline$>11$ & $63(13.3)$ & $4 I I(86.7)$ & \multicolumn{2}{|l|}{ I } \\
\hline
\end{tabular}

(Continued) 
Table 3 (Continued).

\begin{tabular}{|c|c|c|c|c|}
\hline \multirow[t]{3}{*}{ Variables } & \multicolumn{2}{|c|}{ ART Failure } & \multirow[t]{3}{*}{ CHR (95\% Cl) } & \multirow[t]{3}{*}{ AHR $(95 \% \mathrm{Cl})$} \\
\hline & Yes & Censored & & \\
\hline & $\mathbf{N}(\%)$ & $\mathbf{N}(\%)$ & & \\
\hline \multicolumn{5}{|l|}{ Baseline BMI $\left(\mathrm{Kg} / \mathrm{m}^{2}\right)$} \\
\hline$<18.5$ & $61(25.6)$ & I 77 (74.4) & $\mathrm{I} .90(0.82-4.4 \mathrm{I})$ & $1.14(0.73-1.79)$ \\
\hline $18.5-24.9$ & $63(15.4)$ & $345(84.6)$ & \multicolumn{2}{|l|}{ I } \\
\hline$\geq 25$ & $6(7.9)$ & $70(92.1)$ & $3.18(1.37-7.36)$ & $0.74(0.30-1.77)$ \\
\hline \multicolumn{5}{|l|}{ ART side effect } \\
\hline Yes & $10(22.7)$ & $34(77.3)$ & I.42(0.744-2.70) & $1.48(0.72-2.99)$ \\
\hline No & $122(17.6)$ & $57 \mid(82.4)$ & \multicolumn{2}{|l|}{ I } \\
\hline
\end{tabular}

Note: ${ }^{@}$ Independent predictors of first-line ART failure at P-value $<0.05$.

\section{Limitations}

The study was conducted based on a retrospective review of secondary data; hence, certain variables were missed and others might be inappropriately recorded. Moreover, we used clinical and immunological criteria to measure treatment failure, that criteria that are less sensitive and specific to measure treatment.

\section{Conclusion}

The highest rate of ART failure occurred during the earlier months of treatment initiation. Also, not disclosing HIV status, bedridden function status, and baseline low hemoglobin was associated with an increased rate of first-line ART failure. These factors should be considered by health care providers, government and stakeholders for the full success of the effort to reduce HIV related death and increase the quality of life patients living with HIV/AIDS.

\section{Abbreviations}

AHR, Adjusted Hazard Ratio; COR, Crude Hazard Ratio; AIDS, Acquired Immune Deficiency Syndrome; ART, Antiretroviral Therapy; BMI, Body Mass Index; Hg, Hemoglobin; HIV, Human Immune Deficiency Virus; JUSH, Jimma University Specialized Hospital; OIs, Opportunistic infections; WHO, World Health Organization.

\section{Compliance with Ethical Standards}

Ethical clearance to undertake the study was obtained from the Institutional Review Board of Institute of Health Sciences, Jimma University. Permission was also obtained from Jimma University Specialized Hospital (JUSH) administrative body before document review. All information collected from clients' documents was kept anonymous and confidential.

\section{Data Sharing Statement}

The datasets used and analyzed during the current study are available from the corresponding author upon reasonable request.

\section{Acknowledgments}

We would like to pass our special gratitude to Jimma University, Institute of Health Sciences for providing all support to undertake this study. We would also like to thank JUSH for providing all the necessary information for our work.

\section{Author Contributions}

All authors contributed to the conception research questions, setting the objective, designing the study, and data acquisition, analysis, and interpretation. A manuscript was drafted by AA and ZA. All authors contributed towards critically revising the paper, gave final approval of the version to be published, and agreed to be accountable for all aspects of the work.

\section{Disclosure}

All authors declare that they have no competing interests.

\section{References}

1. GBD 2017 HIV collaborators. Global, regional, and national incidence, prevalence, and mortality of HIV, 1980-2017, and forecasts to 2030, for 195 countries and territories: a systematic analysis for the Global Burden of Diseases, Injuries, and Risk Factors Study 2017. Lancet HIV. 2019;6(12):e831-e859. 
2. WHO. Antiretroviral therapy (ART) coverage among all age groups [Internet]. WHO. 2017 [cited February 7, 2017.]. Available from: http:// www.who.int/gho/hiv/epidemic_response/ART/en/. Accessed December 19, 2019.

3. WHO. Global Health Observatory (GHO) data: numberof deaths due to HIV/AIDS [Internet]. WHO. 2017 [cited February 7, 2017]. Available from: http://www.who.int/gho/hiv/epidemic_status/deaths_ text/en/. Accessed December 19, 2019.

4. UNAIDS. How AIDS changed every thing: howworked to achieve the Millennium development goals [Internet]. 2013. Available from: http://www.unaids.org/sites/default/files/media_asset/MDG6Report_ en.pdf. Accessed December 19, 2019.

5. Murphy RA, Sunpath H, Castilla C, et al. Second-line antiretroviral therapy: long-term outcomes in South Africa. JAIDS J Acquir Immune Defic Syndr. 2012;61(2):158-163. doi:10.1097/QAI.0b013e3182615ad1

6. Ramadhani HO, Bartlett JA, Thielman NM, et al. Association of first-line and second-line antiretroviral therapy adherence. Open Forum Infect Dis. 2014;1(2):ofu079-ofu079. doi:10.1093/ofid/ofu079

7. Boyd MA. Current and future management of treatment failure in low- and middle-income countries. Curr Opin HIV AIDS. 2010;5 (1):83-89. doi:10.1097/COH.0b013e328333b8c0

8. Reynolds SJ, Nakigozi G, Newell K, et al. Failure of immunologic criteria to appropriately identify antiretroviral treatment failure in Uganda. AIDS. 2009;23(6):697-700. doi:10.1097/QAD.0b013e3283262a78

9. Rawizza HE, Chaplin B, Meloni ST, et al. Immunologic criteria are poor predictors of virologic outcome: implications for HIV treatment monitoring in resource-limited settings. Clin Infect Dis. 2011;53 (12):1283-1290. doi:10.1093/cid/cir729

10. MPONDO, Bonaventura CT, et al. Prevalence and predictors of immunological failure among HIV-infected adults on HAART in Northwestern Tanzania: a cross sectional study. Tanzan Med J. 2016;27(1):55-69.

11. Ginwalla R, Chama E, Kawamya-Banda F, Thomas R, Mwiya M, Kankasa C. Prevalence of clinical, immunological and irological failure among children on Haart at the university teaching hospital, Lusaka, Zambia. Med J Zambia. 2012;39(3):1-5.

12. Teshome Yimer Y, Yalew AW. Magnitude and predictors of Anti-Retroviral Treatment (ART) failure in private health facilities in Addis Ababa, Ethiopia. PLoS One. 2015;10(5):e0126026. doi:10.1371/journal.pone.0126026

13. Haile D, Takele A, Gashaw K, Demelash H, Nigatu D. Predictors of treatment failure among Adult Antiretroviral Treatment (ART) clients in bale zone hospitals, South Eastern Ethiopia. PLoS One. 2016;11 (10):e0164299. doi:10.1371/journal.pone.0164299

14. Bayou B, Sisay A, Kumie A. Assessment of the magnitude and associated factors of immunological failure among adult and adolescent HIV-infected patients in St. Luke and Tulubolo Hospital, Oromia Region, Ethiopia. Pan Afr Med J. 2015;21. doi:10.11604/ pamj.2015.21.291.6831

15. Yirdaw KD, Hattingh S. Prevalence and predictors of immunological failure among HIV patients on HAART in Southern Ethiopia. Paraskevis D, editor. PLoS One. 2015;10(5):e0125826. doi:10.1371/ journal.pone. 0125826
16. Orrell C, Harling G, Lawn SD, et al. Conservation of first-line antiretroviral treatmentregimen where therapeutic options are limited. Int Med Press. 2007;12(1):83-88.

17. Pujades-Rodríguez M, Balkan S, Arnould L, Brinkhof MAW, Calmy A, AIDS Working Group of MSF. Treatment failure and mortality factors in patients receiving second-line HIV therapy in resource-limited countries. JAMA. 2010;304(3):303-312. doi:10.1001/jama.2010.980

18. UNAIDS. Worrying rates of second-line HIV treatment failure [Internet]. JOHANNESBURG; 2010 [cited February 7, 2017]. Available from: http://www.irinnews.org/news/2010/08/04/worryingrates-second-line-hiv-treatment-failure.

19. Keiser O, Tweya H, Braitstein P, et al. Mortality after failure of antiretroviral therapy in sub-Saharan Africa. Trop Med Int Health. 2010;15(2):251-258. doi:10.1111/tmi.2010.15.issue-2

20. Desmonde S, Eboua F, Malateste K, et al. Determinants of durability of first-line antiretroviral therapy regimen and time from first-line failure to second-line antiretroviral therapy initiation. AIDS. 2015;29 (12):1527-1536. doi:10.1097/QAD.0000000000000707

21. Bacha T, Tilahun B, Worku A. Predictors of treatment failure and time to detection and switching in HIV-infected Ethiopian children receiving first line anti-retroviral therapy. BMC Infect Dis. 2012;12 (1):197. doi:10.1186/1471-2334-12-197

22. Alemu Melsew Y. Rate of immunological failure and its predictors among patients on highly active antiretroviral therapy at Debremarkos Hospital, Northwest Ethiopia: a retrospective follow up study. J AIDS Clin Res. 2013;04(05). doi:10.4172/2155-6113

23. WHO. Consolidated guidelines on the use of antiretroviral drugs for treating and preventing HIV infection: recommendations for a public health approach. [Internet]. 2013 [cited February 7, 2017]. Available from: http://www.ncbi.nlm.nih.gov/books/NBK195400/.

24. Mitra S, Gogolishvili D. Rapid response service. rapid response: disclosure of HIV-positive status [Internet]. Ontario HIV Treatment Network; 2013. Available from: http://publichealth.lacounty.gov/dhsp/ Contractors/MCC/RapidResponseDisclosure.pdf.Accessed December 19, 2019.

25. Vanobberghen FM, Kilama B, Wringe A, et al. Immunological failure of first-line and switch to second-line antiretroviral therapy among HIV-infected persons in Tanzania: analysis of routinely collected national data. Trop Med Int Health. 2015;20(7):880-892. doi:10.1111/ tmi. 12507

26. Muzah BP, Takuva S, Maskew M, Delany-Moretlwe S. Risk factors for discordant immune response among HIV-infected patients initiating antiretroviral therapy: A retrospective cohort study. Afr $J$ HIV Med. 2012;13(4):168-172. doi:10.4102/sajhivmed.v13i4.110

27. Nyesigire Ruhinda E, Bajunirwe F, Kiwanuka J. Anaemia in HIV-infected children: severity, types and effect on response to HAART. BMC Pediatr. 2012;12(1). doi:10.1186/1471-2431-12-170

28. Volberding PA, Levine AM, Dieterich D, et al. Anemia in HIV infection: clinical impact and evidence-based management strategies. Clin Infect Dis. 2004;38(10):1454-1463. doi:10.1086/383031

29. Lumbiganon P, Kosalaraksa P, Bunupuradah T, et al. HIV-infected children in the Asia-Pacific region with baseline severe anemia: antiretroviral therapy and outcomes. Asian Biomed. 2016;10(3):229-234.
HIV/AIDS - Research and Palliative Care is an international, peerreviewed open-access journal focusing on advances in research in HIV, its clinical progression and management options including antiviral treatment, palliative care and public healthcare policies to control viral spread. The manuscript management system is completely online and includes a very quick and fair peer-review system, which is all easy to use. Visit http://www.dovepress.com/testimonials.php to read real quotes from published authors. 